\title{
FORMACIÓN INICIAL DOCENTE, PRÁCTICAS PEDAGÓGICAS Y COMPETENCIAS INTERCULTURALES DE LOS ESTUDIANTES DE CARRERAS DE PEDAGOGÍA DE LA UNIVERSIDAD DE TARAPACÁ, NORTE DE CHILE*
}

\author{
EDUCATIONAL NATIONAL TRAINING, PEDAGOGICAL PRACTICES \\ AND INTERCULTURAL COMPETENCES OF THE STUDENTS OF THE \\ UNDERGRADUATE PROGRAM OF PEDAGOGY AT UNIVERSIDAD \\ DE TARAPACÁ. NORTHERN OF CHILE
}

\author{
Eugenio Sánchez Espinoza**, Alberto Díaz Araya**, \\ Carlos Mondaca Rojas ${ }^{* * *}$ y Juan Carlos Mamani Morales ${ }^{* * * *}$
}

\begin{abstract}
El objetivo del artículo es analizar las competencias interculturales de los estudiantes practicantes de las carreras de pedagogía de las Facultades de Educación y Humanidades y de Ciencias de la Universidad de Tarapacá del Norte de Chile. Se utilizó una metodología mixta donde se aplicó una encuesta que buscó responder acerca de los atributos sociales y culturales del practicante, las características del alumnado al interior de cada una de las aulas, los atributos socioculturales de los establecimientos, la evaluación que desarrollan los practicantes de sus competencias, como también el balance que hacen ellos mismos de la formación en materia intercultural y la evaluación de las competencias interculturales de los estudiantes en práctica. Se caracteriza a partir de los resultados de la muestra (125 encuestados) que 4,8\% de ellos manifiesta tener un alto conocimiento de herramientas teóricas, metodológicas y técnicas para desempeñarse en contextos con diversidad cultural, mientras que 46,6\% de ellos declara poseer un mediano conocimiento, 37,6 indica tener un nulo conocimiento, mientras que $11,2 \%$ no contestan esta pregunta. Lo que sugiere una revisión a la Formación Inicial Docente desde la política institucional para dar cuenta de una formación más pertinente y relevante al contexto de diversidad de nuestra región de Arica y Parinacota.

Palabras claves: Estudiantes practicantes, competencias interculturales, formación inicial docente, Universidad de Tarapacá, Norte de Chile.
\end{abstract}

The objective of the article is to analyze the intercultural competences of the students who practice the pedagogical careers of the Faculties of Education and Humanities and Sciences of the University of Tarapacá in the north of Chile. A mixed methodology was used where a survey was applied that sought to answer on the social and cultural attributes of the practitioner, the characteristics of the students within each of the classrooms, the sociocultural attributes of the establishments, the evaluation that the practitioners of their competences, as well as the balance that they themselves make of the intercultural training and the evaluation of the intercultural competences of the students in practice. It is characterized from the results of the sample (125 respondents) that $4.8 \%$ of them say they have a high knowledge of theoretical, methodological and technical tools to perform in contexts with cultural diversity, while $46.6 \%$ of they declare that they have a medium knowledge, 37.6 indicate that they have no knowledge, while $11.2 \%$ do not answer this question. What suggests a revision to the Initial Teacher Training from the institutional policy to account for a more relevant and relevant training to the context of diversity in our region of Arica and Parinacota.

Key words: Practicing students, Intercultural competences, Initial Teacher Training, University of Tarapacá, North of Chile.

\section{Introducción}

En la frontera norte de Chile se ubica la ciudad de Arica que se constituye como la puerta de entrada para migrantes peruanos, bolivianos, colombianos, ecuatorianos y actualmente venezolanos ${ }^{1}$ que son atraídos por razones económicas en la búsqueda de una mejor calidad de vida. Estos flujos migratorios

\footnotetext{
* Resultado de Proyecto de Investigación UTA No 5732-14. Se agradece el apoyo del Convenio Marco Formación Inicial Docente, UTA1756.

** Universidad de Tarapacá, Departamento de Ciencias Históricas y Geográficas. Arica, Chile. Correo electrónico: esanchez@ uta.cl; albertodiaz@uta.cl

*** Universidad de Tarapacá, Departamento de Educación. Arica, Chile. Correo electrónico: cemondacar@uta.cl

*****Universidad de Tarapacá, Departamento de Español. Arica, Chile. Correo electrónico: mamanimorales.juancarlos@ gmail. com
} 
dan a la ciudad un carisma cosmopolita y multicultural, que se suma a un rico pasado histórico republicano, colonial y prehispánico multiétnico, donde confluyen distintos grupos culturales, como aymaras, quechuas, españoles, esclavos africanos y colonias de italianos, griegos, chinos, entre otros.

Actualmente en el plano educativo, desde la educación parvularia hasta la educación superior, es posible apreciar una composición heterogénea del estudiantado en la región. Las aulas ya no solo están integradas por estudiantes de ascendencia aymara $^{2}$, como en otras décadas y en quienes el Estado centró su acción por medio del programa de Educación Intercultural Bilingüe ${ }^{3}$, más bien hoy estas son un auténtico mosaico de identidades y diversidades culturales en el que el docente del siglo XXI debe adquirir competencias pertinentes en su formación inicial docente.

El educar formalmente a la diversidad cultural de la región, con grupos extremadamente heterogéneos al interior de los espacios educativos, con una población en riesgo social ${ }^{4}$ que muchas veces, ante la falta de oportunidades, manifiesta una suerte de pérdida del sentido del saber o el aprender (Galvis, 2007), es una muestra de la complejidad del escenario local para el trabajo docente. Es importante consignar que la formación inicial docente no solo se relaciona con la instrucción, también con la sociedad que anhelamos y en la que deseamos vivir.

Esta sociedad día a día es explícitamente más heterogénea. Por consiguiente, surge una demanda más emergente en los planes educativos por construir sociedades más inclusivas e interculturales (Leiva 2012). Es en ese contexto donde el profesor puede desarrollar y fortalecer en sus estudiantes determinadas competencias y saberes, en desmedro de otros (Geeregat et al., 2012), para el logro de una convivencia armónica y tolerante. Por tanto, en una región con diversidad adquiere relevancia la aprehensión y comprensión del entramado cultural, como parte de la identidad del sujeto.

Lo anterior deriva en que el pedagogo debe ser un profesional crítico y reflexivo ante la diversidad (Adreucci, 2013). Es decir, debe poseer competencias interpersonales de orden intercultural para formar estudiantes tolerantes, con una actitud y visión positiva hacia la diversidad social y cultural ${ }^{5}$. Por tanto, si ellas no fueron desarrolladas en su formación inicial, difícilmente podrá lograrlas en los estudiantes (Aguaded, 2006) durante su ejercicio profesional.
En el caso de los futuros profesionales de la educación, formados en la Universidad de Tarapacá, deben desarrollar su práctica profesional en ese contexto educativo que se caracteriza por la diversidad cultural. Es decir, en situaciones en donde deben atender procesos de enseñanza-aprendizaje en aulas que presentan estudiantes de las minorías étnicas locales unida a los hijos de migrantes. Frente a ello la formación inicial docente, al interior de esta casa de estudios, fomenta el desarrollo de habilidades y competencias de inclusión e interculturalidad (Gimeno, 2008) en sus futuros pedagogos. Ello se basa en el conocimiento de la historia e identidad cultural a nivel local, articulada con lo global.

Sin embargo, existen investigaciones que manifiestan que las prácticas profesionales, si bien es cierto, son el espacio propicio para desplegar las competencias alcanzadas en el proceso de formación, solo resultan ser momentos formativos. Esto quiere decir que los estudiantes de pedagogía solo desarrollan estrategias rutinarias (Correa, 2011) con el fin de aprobar esta última etapa de su formación, evitando riesgos que evidencien sus falencias formativas de pregrado.

En consecuencia, es válido preguntarse: ¿Cuál es el nivel de logro de las competencias interpersonales de orden intercultural en los estudiantes de pedagogía en práctica profesional?, si ¿el proceso de formación inicial, que recibió el estudiante en práctica profesional, permite que se desenvuelva competentemente en espacios multiculturales fronterizos? y si ila práctica educativa desarrollada por los estudiantes de pedagogía en práctica profesional demuestra una competencia intercultural que les permita el reconocimiento y manejo de las diferencias culturales en el aula?

En relación con lo expuesto, este artículo analiza la Formación Inicial del Docente en materia de competencias interculturales. Lo anterior, mediante un estudio aplicado a los estudiantes de pedagogía de las Facultad de Educación y Humanidades (FEH) y la Facultad de Ciencias (FC) de la Universidad de Tarapacá (UTA), que ya han recibido todos los niveles de instrucción disciplinaria y pedagógica y que se encuentran desarrollando su práctica profesional final en las aulas ariqueñas.

\section{Metodología}

La metodología utilizada para analizar las competencias interculturales de los practicantes 
de las carreras de pedagogía de las Facultades de Educación y Humanidades (FEH) y Ciencias (FC) de la Universidad de Tarapacá (UTA) es de naturaleza mixta. Esto se debe al carácter focalizado del estudio, el que requiere ser analizado desde múltiples dimensiones, como lo son los atributos sociales y culturales del practicante, las características del alumnado al interior de cada una de las aulas, los atributos socioculturales de los establecimientos, la evaluación que desarrollan los practicantes de sus competencias, como también el balance que hacen ellos mismos de la formación entregada por la UTA en materia intercultural y, finalmente, la evaluación de las competencias interculturales de los estudiantes en práctica.

En el marco de la investigación desarrollada durante el 2014 una de las primeras acciones metodológicas ejecutadas fue la gestión e implementación de reuniones entre el equipo de trabajo y las autoridades académicas de la FEH y la FC; estos encuentros facilitaron las condiciones para la recolección de datos e involucraron a las decanaturas en un proceso de diálogo y retroalimentación vinculado a la necesidad de generar políticas universitarias, asociadas a las prácticas profesionales y al potenciamiento de las competencias interculturales en la formación inicial de profesores.

También sostuvimos reuniones con la Dirección de Docencia (DIDO) de la UTA, las que permitieron acceder a datos referidos al proceso de formación inicial de profesores. En paralelo, se construyó una base de datos con información general acerca de la población estudiada a partir de información entregada por la DIDO, el Centro de Prácticas Pedagógicas (CPP) y la Unidad de Registraduría 6 de la UTA.

Recolectados los antecedentes generales de los practicantes, se procedió a operacionalizar las variables de estudio, lo que se manifestó en la formulación de un instrumento que buscó responder preguntas organizadas en diferentes dimensiones, como lo son: información general concerniente a los estudiantes en práctica profesional de pedagogía de la UTA, sus competencias interculturales y los contextos socioeducativos en los que se desenvuelven.

La encuesta construida se sometió a una prueba de control por medio del encuestaje piloto a un número reducido de practicantes con el objetivo de evitar ambigüedades en las preguntas y de evaluar si existían algunos problemas de comprensión en los sistemas de indicadores propuestos para cada una de las variables a medir. Seguidamente, implementamos reuniones de coordinación con el CPP y cada uno de los coordinadores pedagógicos de las prácticas profesionales por especialidad, además de sensibilizar a los practicantes respecto de los objetivos y relevancia del estudio; esto finalizó con la aplicación del instrumento a cada uno de ellos en las reuniones de coordinación con sus respectivos coordinadores pedagógicos. El proceso de relevamiento de las encuestas fue monitoreado por el equipo de investigación, el CPP y las jefaturas de las carreras comprometidas; tuvo una duración de aproximadamente dos meses.

El instrumento está organizado en cinco grandes áreas. La primera de ellas busca recopilar información general, de carácter sociocultural de los practicantes; la segunda, recopila información de las características administrativas, sociales y culturales de los establecimientos donde cada uno de los casos estudiados se desempeña; la tercera parte recopila información pertinente a la percepción que poseen los practicantes respecto de si sus instituciones de práctica poseen o no características multiculturales.

Existe una cuarta parte en la que se indaga la opinión que tienen los practicantes por sus propias competencias para enfrentar contextos educativos multiculturales. También allí se evalúan si los conocimientos adquiridos durante su proceso de formación inicial docente les entregó o no competencias para enfrentar los escenarios educativos señalados. Finalmente el instrumento contó de una quinta parte, en donde los practicantes exponen sus actitudes ante ciertos predictores y afirmaciones, en la que se busca identificar actitudes de ellos frente a eventuales escenarios asociados con los contextos originales de desempeño.

El resultado del proceso de recolección de datos arrojó $89,9 \%$ de encuestas válidamente contestadas. Eso equivale a 125 de 139 estudiantes en práctica. Además, en 4 carreras, de las 8 comprometidas, se logró aplicar la encuesta a la totalidad de los casos $(100 \%)$. Las razones asociadas a las encuestas faltantes son variadas: en algunos casos los practicantes no asistieron a sus respectivas actividades en los momentos en que se tomó la encuesta; en otros casos, la ausencia de encuestas correspondió a la anulación de algunos instrumentos al momento de tabular, ya que estos no estaban contestados, como asimismo se notificaron retiros de estudiantes en práctica profesional. 
En la Tabla 1 es posible ver el número oficial de practicantes de pedagogía durante el segundo semestre del 2014, los que se encuentran distribuidos por carrera. Igualmente es posible observar el número y porcentaje de encuestas aplicadas distribuido por carrera.

Una vez aplicada la encuesta, implementamos la tabulación de los resultados en un software estadístico como el SPSS procediendo a identificar de los estadísticos descriptivos (medidas de tendencia central y de dispersión) de cada una de las variables comprometidas, y en virtud de ello procedimos a generar las respectivas tablas de contingencia que nos permitieron cruzar variables para acceder a información más detallada.

Luego desarrollamos un proceso de categorización a base de la agrupación de variables organizadas con sistemas de indicadores similares, fundamentalmente aquellas organizadas en la Escala de Likert para la identificación de las competencias interculturales y rasgos discriminatorios en los estudiantes. A partir de la obtención de la información generada por los estadísticos, las tablas de contingencia y el proceso de construcción de categorías agrupadas, procedemos a presentar los principales resultados.

\section{Caracterización de la población estudiada}

\section{A. Aspectos generales}

Como una medida inicial para el análisis de las competencias interculturales se caracterizó social y culturalmente a los estudiantes en práctica profesional de las diversas carreras de pedagogía de la UTA. En este sentido abordamos el cruce de variables como sexo, nacionalidad, adscripción étnica y pertenencia étnica particular, a base de una distribución minuciosa de los resultados por carrera, con el fin de identificar las características específicas propias de los practicantes.

Del $100 \%$ de los estudiantes en práctica encuestados, es decir, 125 casos, el 99,2\% manifestaron ser chilenos y solo un caso afirmó poseer una nacionalidad distinta a la chilena, lo que corresponde al $0,8 \%$. Asimismo, al interior de los practicantes chilenos existe $21,3 \%$ (26 casos) que informa poseer familiares extranjeros, y de ellos $57,7 \%$ (15 casos) indicó que sus parientes pertenecen a algún grupo étnico.

Además, el cruce de variables descriptivas índico que el $60 \%$ de los estudiantes que afirma tener familiares extranjeros declara que sus parientes pertenecen al pueblo originario aymara, y $20 \%$, es decir, 3 casos, es afrodescendiente. Lo anterior evidencia la vinculación de los encuestados a contextos culturalmente diversos.

Igualmente es importante señalar que de los encuestados el 30,4\% (38 casos) son hombres y el $68,8 \%$ (86 casos) son mujeres, estableciéndose un dominio numérico claro de estas últimas. Por consiguiente, la distribución por sexo en las carreras involucradas en la investigación el predominio femenino está en el programa académico de Pedagogía en Biología y Ciencias Naturales, donde 33,3\% (2 casos) son hombres, y 50\% (3 casos) son mujeres y un estudiante que no identifica su género cierra el $100 \%$ en esta carrera.

Tabla 1. Número oficial de estudiantes en práctica profesional pedagógica de la Universidad de Tarapacá y número total de encuestados.

\begin{tabular}{lccccc}
\hline \multicolumn{1}{c}{ Carreras } & Facultad & $\begin{array}{c}\mathrm{N}^{\circ} \text { de } \\
\text { practicantes }\end{array}$ & Encuestados & \% & $\begin{array}{c}\% \\
\text { Encuesta }\end{array}$ \\
\hline Pedagogía en Educación Básica & FEH & 28 & 22 & 78,5 & 17,6 \\
Educación Parvularia & FEH & 12 & 9 & 75,0 & 7,2 \\
Pedagogía en Historia y Geografía & FEH & 26 & 22 & 84,6 & 17,6 \\
Pedagogía en Educación Física & FEH & 21 & 21 & 100,0 & 16,8 \\
Pedagogía en Castellano y Comunicación & FEH & 17 & 17 & 100,0 & 13,6 \\
Pedagogía en Inglés & FEH & 23 & 22 & 95,6 & 17,6 \\
Pedagogía en Matemática y Computación y Física & FC & 6 & 6 & 100,0 & 4,8 \\
Pedagogía en Biología y Ciencias Naturales & FC & 6 & 6 & 100,0 & 4,8 \\
& & 139 & 125 & 89,9 & 100,0 \\
\hline
\end{tabular}

Fuente: CPP y Encuesta para la identificación de competencias interculturales de practicantes de carreras de Pedagogía de la UTA. 
En el caso de Pedagogía en Castellano y Comunicación la brecha es mayor, es decir, existe solo $5,9 \%$ ( 1 caso) de estudiantes hombres y el 94,1\% (16 casos) son mujeres. La distribución por género en la carrera de Pedagogía en Educación Básica mantiene una tendencia similar, existiendo $18,2 \%$ (4 casos) de hombres y $81,8 \%$ (18 casos) de mujeres. Finalmente, en la carrera de Pedagogía en Inglés 13,6\% (3 casos) son hombres y 86,4\% (19) son mujeres.

Esta brecha donde el elemento femenino es el preponderante, se modifica hacia el equilibrio en el caso de la Pedagogía en Educación Física, donde el 47,6\% (10 casos) son hombres y 52,4\% (11 casos) son mujeres y en Pedagogía en Matemáticas, Computación y Física ambos sexos están equiparados. Pero en el caso de Pedagogía en Educación Parvularia la distribución se modifica al extremo al existir $100 \%$ ( 9 casos) de mujeres.

En el caso de la carrera de Pedagogía en Historia y Geografía la tendencia se invierte, existiendo un mayor número de población masculina, con $68,2 \%$ ( 15 casos) de hombres y $31,8 \%$ ( 7 casos) de mujeres.

\section{B. Estudiantes en práctica y pueblos originarios}

Por otra parte y en relación con los aspectos asociados a la forma en que los estudiantes en práctica se conciben culturalmente se da aquel relativo al comportamiento que asumen al momento de ser consultados respecto de su pertenencia a algún grupo étnico. En consecuencia, es posible afirmar que del total de encuestados existe $24 \%$ (30 casos) que afirma pertenecer a alguna etnia. Asimismo, un aspecto que llama la atención se relaciona con que el mayor porcentaje de quienes afirman ser indígenas son mujeres, con $73,3 \%$, es decir, 22 casos.

Al mismo tiempo es posible estimar una distribución heterogénea de los estudiantes pertenecientes a pueblos originarios en las carreras de la FEH de la UTA en el siguiente desagregado:

En Pedagogía en Educación Básica el 16,7\% afirma pertenecer a algún grupo étnico y en el caso de Pedagogía en Castellano y Comunicación 35,3\% afirma lo mismo. En Pedagogía en Educación Básica 27,3\% afirma ser indígena; en la carrera de Educación Física 14,3\%; y en Pedagogía en Educación Parvularia el porcentaje es de poco más del 33,3\%. De forma semejante en Pedagogía en Historia y Geografía el porcentaje de practicantes indígenas es de 13,6\% y en la carrera de Pedagogía en Inglés el 27,3\% de los encuestados se adscribe a algún grupo étnico. Finalmente, en el caso de las carreras de Pedagogía en Matemáticas, Computación y Física la tendencia presenta un significativo $33,3 \%$. En otras palabras y de forma específica, es relevante indicar que del total de los estudiantes que afirman pertenecer a un pueblo originario $53,6 \%$ (15 casos) son aimaras, $10,7 \%$ (3 casos) son quechuas, el 17,9\% (5 casos) de ellos son mapuches, el 7,1\% ( 2 casos) de ellos son diaguitas y el 7,1\% (2 casos) afirma ser afrodescendiente ${ }^{7}$.

En un aspecto paralelo a la adscripción étnica, la información procesada arroja que 34,3\% (37 casos) del total de encuestados indica tener un familiar perteneciente a algún grupo étnico o afrodescendiente. Del grupo anterior 18 afirman tener familiares aimaras $(58,1 \%)$; dos casos son quechuas $(6,5 \%)$; un caso es diaguitas $(0,8 \%)$ y seis casos poseen familiares afrodescendientes $(16,6 \%)$. Llama mucho la atención el hecho de que existen 9 casos que afirman no pertenecer a algún grupo étnico pero a la vez afirman tener familiares pertenecientes a algún pueblo originario. Es factible subrayar que el estudiantado vinculado al área profesional de historia y geografía presentan algunas características socioculturales particulares. Primero, en contraste con las demás pedagogías del área humanística propiamente, es la que se compone mayoritariamente de varones. Segundo, presenta un número reducido de estudiantes procedentes de pueblos indígenas.

Desplegado este panorama acerca de la adscripción sociocultural de los estudiantes en práctica profesional es claro que ella no es homogénea y más bien tiende a emparentarse con la estructura cultural regional manifestada en la primera parte de este trabajo. Por último, los estadísticos evidencian la adscripción a diversos grupos étnicos, junto con un número no menor que menciona poseer familiares de otras nacionalidades. Es por ello, y en consideración a los objetivos de nuestro estudio, que en las páginas siguientes se identificarán las características generales de las aulas donde los futuros pedagogos se desenvuelven, de manera tal de poder evaluar si la estructura social y cultural de dichos espacios se correlaciona positivamente 
con las características de los estudiantes en práctica evaluación de sus competencias interculturales ${ }^{8}$ y qué significado tiene ello desde la óptica de la

(Tablas 2 y 3 ).

Tabla 2. Cuadro síntesis global de porcentajes por carrera y por variables de género, pertenencia o adscripción indígena y etnia.

\begin{tabular}{|c|c|c|c|c|c|c|c|c|c|c|c|c|c|c|c|c|c|c|c|}
\hline & \multicolumn{2}{|c|}{$\begin{array}{c}\text { Pedagogía } \\
\text { en Biología } \\
\text { y Ciencias } \\
\text { Naturales }\end{array}$} & \multicolumn{2}{|c|}{$\begin{array}{c}\text { Pedagogía } \\
\text { en } \\
\text { Castellano y } \\
\text { Comunicación }\end{array}$} & \multicolumn{2}{|c|}{$\begin{array}{l}\text { Pedagogía en } \\
\text { Educación } \\
\text { Básica }\end{array}$} & \multicolumn{2}{|c|}{$\begin{array}{l}\text { Pedagogía en } \\
\text { Educación } \\
\text { Física }\end{array}$} & \multicolumn{2}{|c|}{$\begin{array}{l}\text { Pedagogía en } \\
\text { Educación } \\
\text { Parvularia }\end{array}$} & \multicolumn{2}{|c|}{$\begin{array}{c}\text { Pedagogía } \\
\text { en Historia y } \\
\text { Geografía }\end{array}$} & \multicolumn{2}{|c|}{$\begin{array}{l}\text { Pedagogía en } \\
\text { Inglés }\end{array}$} & \multicolumn{3}{|c|}{$\begin{array}{l}\text { Pedagogía en } \\
\text { Matemáticas No } \\
\text { Computación Contesta } \\
\text { y Física }\end{array}$} & \multicolumn{2}{|c|}{ Total } \\
\hline & $\mathrm{N}^{\mathrm{o}}$ & $\%$ & $\mathrm{~N}^{\mathrm{O}}$ & $\%$ & $\mathrm{~N}^{\mathrm{o}}$ & $\%$ & $\mathrm{~N}^{\mathrm{o}}$ & $\%$ & $\mathrm{~N}^{\mathrm{o}}$ & $\%$ & $\mathrm{~N}^{\mathrm{o}}$ & $\%$ & $\mathrm{~N}^{\mathrm{o}}$ & $\%$ & $\mathrm{~N}^{\mathrm{o}}$ & $\%$ & $\mathrm{~N}^{\circ}$ & $\mathrm{N}^{\mathrm{o}}$ & $\%$ \\
\hline Masculino & 2 & 1,6 & 1 & 0,8 & 4 & 3,2 & 10 & 8 & 0 & 0 & 15 & 12 & 3 & 2,4 & 3 & 2,4 & 0 & 38 & 100 \\
\hline Femenino & 3 & 2,4 & 16 & 12,8 & 18 & 14,4 & 11 & 8,8 & 9 & 7,2 & 7 & 5,6 & 19 & 15,2 & 3 & 2,4 & 0 & 86 & 100 \\
\hline No contesta & 1 & 0 & 0 & 0 & 0 & 0 & 0 & 0 & 0 & 0 & 0 & 0 & 0 & 0 & 0 & 0 & 1 & 1 & 100 \\
\hline Total & 5 & 4 & 17 & 13,6 & 22 & 17,6 & 21 & 16,8 & 9 & 7,2 & 22 & 17,6 & 22 & 17,6 & 6 & 4.8 & 1 & 125 & 100 \\
\hline Indígena & 1 & 3,3 & 6 & 20 & 6 & 20 & 3 & 10 & 3 & 10 & 3 & 10 & 6 & 20 & 2 & 6,6 & 0 & 30 & 100 \\
\hline No indígena & 5 & 5,3 & 11 & 11,8 & 15 & 16 & 17 & 18 & 6 & 6,4 & 19 & 20,4 & 16 & 17 & 4 & 4,3 & 0 & 93 & 100 \\
\hline Total & 6 & 4,8 & 17 & 13 & 21 & 17 & 20 & 16,2 & 9 & 7,3 & 22 & 17,8 & 22 & 17,8 & 6 & 4,88 & 2 & 125 & 100 \\
\hline Aimara & 0 & 0 & 4 & 26,6 & 5 & 33,3 & 0 & 0 & 2 & 13,3 & 1 & 6,6 & 2 & 13,3 & 1 & 6,6 & 0 & 15 & 100 \\
\hline Quechua & 0 & 0 & 1 & 25 & 1 & 25 & 0 & 0 & 1 & 25 & 0 & 0 & 0 & & 1 & 25 & 0 & 4 & 100 \\
\hline Mapuche & 0 & 0 & 0 & 0 & 0 & 0 & 2 & 50 & 0 & 0 & 1 & 25 & 1 & 25 & 0 & 0 & 0 & 4 & 100 \\
\hline Atacameño & 1 & 50 & 0 & 0 & 1 & 50 & 0 & 0 & 0 & 0 & 0 & 0 & 0 & 0 & 0 & 0 & 0 & 2 & 100 \\
\hline Afrodescendientes & 0 & 0 & 0 & 0 & & 0 & 0 & 0 & 0 & 0 & 1 & 50 & 0 & 0 & 1 & 50 & 0 & 2 & 100 \\
\hline
\end{tabular}

Tabla 3. Cuadro de porcentajes por carrera y por variables de género pertenencia o adscripción indígena.

\begin{tabular}{|c|c|c|c|c|c|c|c|c|c|c|c|c|c|c|c|}
\hline \multirow{3}{*}{$\begin{array}{l}\text { Unidad } \\
\text { (Carrera) }\end{array}$} & \multicolumn{7}{|c|}{ Sexo } & \multirow{3}{*}{$\begin{array}{c}\text { Unidad } \\
\text { (Carrera) }\end{array}$} & \multicolumn{7}{|c|}{ Pertenencia étnica } \\
\hline & \multicolumn{2}{|c|}{ Masculino } & \multicolumn{2}{|c|}{ Femenino } & \multirow{2}{*}{$\begin{array}{c}\text { No } \\
\text { con- } \\
\text { testa }\end{array}$} & \multicolumn{2}{|c|}{ Total } & & \multicolumn{2}{|c|}{ Pertenece } & \multicolumn{2}{|c|}{$\begin{array}{c}\text { No } \\
\text { pertenece }\end{array}$} & \multirow{2}{*}{$\begin{array}{c}\text { No } \\
\text { con- } \\
\text { testa }\end{array}$} & \multicolumn{2}{|c|}{ Total } \\
\hline & $\mathrm{N}^{\mathrm{o}}$ & $\%$ & $\mathrm{~N}^{\mathrm{o}}$ & $\%$ & & $\mathrm{~N}^{\mathrm{o}}$ & $\%$ & & $\mathrm{~N}^{\mathrm{o}}$ & $\%$ & $\mathrm{~N}^{\mathrm{o}}$ & $\%$ & & $\mathrm{~N}^{\mathrm{o}}$ & $\%$ \\
\hline Pedagogía en & & & & & & & & Pedagogía en & & & & & & & \\
\hline $\begin{array}{l}\text { Biología y Ciencias } \\
\text { naturales. }\end{array}$ & 2 & 33,3 & 3 & 50 & 1 & 6 & 100 & $\begin{array}{l}\text { Biología y Ciencias } \\
\text { naturales. }\end{array}$ & 1 & 16,7 & 5 & 83,3 & 0 & 6 & 100 \\
\hline Pedagogía en & & & & & & & & Pedagogía en & & & & & & & \\
\hline $\begin{array}{l}\text { Castellano y } \\
\text { Comunicación. }\end{array}$ & 1 & 5,9 & 16 & 94,1 & 0 & 17 & 100 & $\begin{array}{l}\text { Castellano y } \\
\text { Comunicación. }\end{array}$ & 6 & 35,3 & 11 & 64,7 & 0 & 17 & 100 \\
\hline $\begin{array}{l}\text { Pedagogía en } \\
\text { Educación } \\
\text { Básica. }\end{array}$ & 4 & 18,2 & 18 & 81,8 & 0 & 22 & 100 & $\begin{array}{l}\text { Pedagogía en } \\
\text { Educación Básica. }\end{array}$ & 6 & 27,3 & 15 & 68,2 & 1 & 22 & 100 \\
\hline $\begin{array}{l}\text { Pedagogía en } \\
\text { Educación Física. }\end{array}$ & 10 & 47,6 & 11 & 52,4 & 0 & 21 & 100 & $\begin{array}{l}\text { Pedagogía en } \\
\text { Educación Física. }\end{array}$ & 3 & 14,3 & 17 & 81 & 1 & 21 & 100 \\
\hline $\begin{array}{l}\text { Pedagogía en } \\
\text { Educación } \\
\text { Parvularia. }\end{array}$ & 9 & 100 & 0 & 0 & 0 & 9 & 100 & $\begin{array}{l}\text { Pedagogía en } \\
\text { Educación } \\
\text { Parvularia. }\end{array}$ & 3 & 33,3 & 6 & 66,7 & 0 & 9 & 100 \\
\hline $\begin{array}{l}\text { Pedagogía en } \\
\text { Historia y Geografía. }\end{array}$ & 15 & 68,2 & 7 & 31,8 & 0 & 22 & 100 & $\begin{array}{l}\text { Pedagogía en } \\
\text { Historia y Geografía. }\end{array}$ & 3 & 13,6 & 19 & 86,4 & 0 & 22 & 100 \\
\hline Pedagogía en Inglés. & 3 & 13,6 & 19 & 86,4 & 0 & 22 & 100 & Pedagogía en Inglés. & 6 & 27,3 & 16 & 72,7 & 0 & 22 & 100 \\
\hline $\begin{array}{l}\text { Pedagogía en } \\
\text { Matemáticas, } \\
\text { Computación y } \\
\text { Física. }\end{array}$ & 3 & 50 & 3 & 50 & 0 & 6 & 100 & $\begin{array}{l}\text { Pedagogía en } \\
\text { Matemáticas, } \\
\text { Computación y } \\
\text { Física. }\end{array}$ & 2 & 33,3 & 4 & 66,7 & 0 & 6 & 100 \\
\hline
\end{tabular}




\section{Clasificación de los centros de práctica profesional}

Así como hemos entregado antecedentes sociales y culturales respecto de la población estudiada, se hace ineludible exponer antecedentes de los establecimientos educacionales en los que se desempeñan los estudiantes en práctica de la FEH y la FC de la UTA. El objetivo de esto es poder evaluar sus competencias interculturales desde contextos concretos, debido a que los casos estudiados no se encuentran en un espacio social abstracto, sino que en comunidades educativas específicas.

\section{A. Tipo de establecimiento educacional}

En este sentido, resulta relevante mencionar que los 125 casos estudiados, es decir el 100\%, se encuentran distribuidos en 31 instituciones, de estas, 37,5\% (12 casos) son Colegios, el 18,7\% (6 casos) son Escuelas, $21,8 \%$ (7 casos) corresponde a Liceos y 9,4\% (3 casos) a Jardines Infantiles.

El 9,7\% de los casos fueron categorizados en la figura de "Otros", donde se encuentran las siguientes instituciones: Universidad de Tarapacá; Caja de Compensación Los Andes y Centro de Salud Familiar Dr. Remigio Sapunar, el que depende administrativamente, de la Corporación Municipal de Desarrollo Social de la comuna de Arica. Cada uno de los casos mencionados representa 3,2\%.

Junto con lo señalado e intentando otorgar un valor a la presencia de los practicantes de la UTA como parte de la realidad de las comunidades educativas señaladas, es relevante exponer aquí la distribución de los casos estudiados al interior de las instituciones educativas según su tipo.

Por consiguiente, los Colegios agrupan al $41,4 \%$ (52 casos) de los practicantes y las Escuelas al 8,8\% de los casos. Los Liceos acogen a 31,2\% (39 casos) y los Jardines Infantiles aceptan al $4 \%$ ( 5 casos) de los estudiantes en periodo de práctica profesional.

\section{B. Dependencia administrativa de los establecimientos educacionales}

En relación con la dependencia administrativa y fuentes de financiamiento de cada uno de los establecimientos es interesante señalar que 50\% (16 casos) de los establecimientos son municipales, mientras que el $31,3 \%$ de estos son particulares subvencionados y solo $9,4 \%$ (3 casos) son particulares privados.

En la categoría de "otras fuentes de financiamiento" solo existen tres instituciones, siendo las mismas anteriormente mencionadas en la categoría de "otros" para el tipo de establecimiento.

Respecto de las instituciones señaladas con "otra fuente de financiamiento", sostenemos que una es de carácter municipal $(3,1 \%)$ como es el caso del CESFAM Dr. Remigio Sapunar, la otra $(3,1 \%)$ depende del MINEDUC, hacemos referencia a la UTA, y junto con ellas se encuentra la Caja de Compensación Los Andes (3,1\%) que depende administrativamente de sí misma, ya que es de carácter privado.

Ahora bien, de la misma forma como se procedió con la variable que indica el tipo de establecimiento, decidimos explorar la forma en que están disgregados los practicantes de la UTA según el tipo de financiamiento y dependencia administrativa de las instituciones que los acogen. Se pudo establecer que el 48,8\% (61, casos) de los practicantes de la UTA se encuentran integrados en instituciones de carácter municipalizadas, mientras que solo $3,2 \%$ (4 casos) de ellos desarrollan sus prácticas al interior de establecimientos particulares.

Quienes se desempeñan en establecimientos particulares subvencionados representan al 37,6\% (47 casos) de los practicantes y 2,4\% (3 casos) lo hacen en otro tipo de instituciones, de estas, dos son dependientes de la Junta Nacional de Jardines Infantiles (JUNJI) y la UTA dependiente del MINEDUC.

Los antecedentes ya expuestos nos señalan un camino muy interesante, ya que gran parte de los practicantes de la UTA se desempeñan en establecimientos de educación pública. Eso, sin lugar a dudas, abre puertas al análisis que se podrá apreciar en el siguiente apartado. Allí se verá en qué tipo de establecimientos, en opinión de los mismos estudiantes en práctica, se agrupa la mayor cantidad de estudiantes de otras nacionalidades o pertenecientes a grupos étnicos. Esto, desde ya, se considera un avance respecto del conocimiento de la realidad en la que se desenvuelven los casos estudiados como también las condiciones para la evaluación de sus competencias. 
Tabla 4. Distribución de practicantes por tipo de establecimiento.

\begin{tabular}{|c|c|c|c|c|c|c|c|c|c|c|c|}
\hline \multicolumn{3}{|c|}{ Tipo de establecimiento } & \multicolumn{3}{|c|}{$\begin{array}{l}\text { Distribución de los } \\
\text { practicantes según tipo } \\
\text { de establecimiento }\end{array}$} & \multicolumn{3}{|c|}{$\begin{array}{l}\text { Número de } \\
\text { establecimientos según } \\
\text { tipo de financiamiento }\end{array}$} & \multicolumn{3}{|c|}{$\begin{array}{l}\text { Distribución de los } \\
\text { practicantes según tipo de } \\
\text { financiamiento recibido }\end{array}$} \\
\hline & $\mathrm{N}^{\mathrm{o}}$ & $\%$ & & $\mathrm{~N}^{\mathrm{o}}$ & $\%$ & & $\mathrm{~N}^{\mathrm{o}}$ & $\%$ & & $\mathrm{~N}^{\mathrm{o}}$ & $\%$ \\
\hline Colegio & 12 & 37,5 & Colegio & 52 & 41,6 & Municipal & 16 & 50 & Municipal & 61 & 48,8 \\
\hline Escuela & 6 & $18,7 \mathrm{I}$ & Escuela & 11 & 8,8 & $\begin{array}{l}\text { Particular } \\
\text { subvencionado }\end{array}$ & 10 & 31,3 & $\begin{array}{l}\text { Particular } \\
\text { subvencionado }\end{array}$ & 47 & 37,6 \\
\hline Liceo & 7 & $21,8 \mathrm{I}$ & Liceo & 39 & 4 & Particular & 3 & 9,4 & Particular & 4 & 3,2 \\
\hline Jardín Infantil & 3 & $9,4 \mathrm{~J}$ & Jardín Infantil & 5 & 31,2 & Otro & 3 & 9,4 & Otro & 3 & 2,4 \\
\hline Otro & 3 & 9,4 & Otro & 4 & 3,2 & Total & 32 & 100 & No contesta & 10 & 8 \\
\hline \multirow[t]{2}{*}{ Total } & 32 & $100 \mathrm{I}$ & No contesta & 14 & 11,2 & & & & & & \\
\hline & & & Total & 125 & 100 & & & & Total & 125 & 100 \\
\hline
\end{tabular}

\section{Caracterización del espacio de desempeño}

\section{A. Identificación de aulas multiculturales por parte de los estudiantes en práctica pedagógica}

El análisis descriptivo de la totalidad de las encuestas pone en evidencia que existe $43,2 \%$ (54 casos) de practicantes que afirman tener estudiantes de otras nacionalidades en sus aulas. Esas nacionalidades señaladas por los encuestados son 12 y cada una de ellas tiene un nivel de representación diferenciado, las que pasamos a detallar.

Las nacionalidades más recurrentes son la boliviana con $37,3 \%$ ( 28 casos) seguida por la peruana con $34,76 \%$ ( 26 casos), colombianos con 13 casos, lo que equivale a $17,3 \%$, y con un valor mucho menor se encuentran los ecuatorianos con 2,6\%.

Igualmente algunos de los estudiantes en práctica indican tener alumnos de nacionalidades distintas a las ya señaladas (alemanes, argentinos, estadounidenses, ingleses, paraguayos y venezolanos), teniendo cada una de ellas una representación mucho menor, equivalente al 1,3\% (1 caso).

Un dato relevante al evaluar la distribución de los estudiantes de otras nacionalidades, a juicio de los practicantes, dice relación con el tipo de establecimientos en el que se encuentran agrupados.

Para ello hemos desarrollado un cruce de variables entre el tipo de dependencia administrativa de los establecimientos y el país de origen de los estudiantes extranjeros de los practicantes. Es posible observar que del total de los casos estudiados, $61,1 \%$ (33 casos) pertenece a establecimientos municipales, $31,4 \%$ (17 casos) pertenece a establecimientos particulares subvencionados y $3,7 \%$ ( 2 casos) son particulares. Este último valor es idéntico para los establecimientos dependientes de la Junta Nacional de Jardines Infantiles (JUNJI).

Al valorar el porcentaje de encuestados que manifiesta tener alumnos de otras nacionalidades en relación con la distribución total por tipo de dependencia administrativa, los resultados son igualmente interesantes. Por ejemplo, del total de practicantes en establecimientos municipalizados el $55 \%$ (33 casos) indica tener estudiantes de otras nacionalidades en sus aulas y el 36,1\% (17 casos) de los casos estudiados señala la misma situación, pero en establecimientos particulares subvencionados ${ }^{9}$.

\section{B. Estudiantes de pueblos originarios}

Ahora bien, intentando explorar en aquellos aspectos referidos a la población escolar perteneciente a algún grupo étnico, es relevante mencionar que el 63,2\% (79 casos) indica tener población indígena en sus aulas.

Los grupos étnicos que los practicantes reconocen en sus aulas son, fundamentalmente, aymaras con $78 \%$ (78 casos), la etnia mapuche está representada por $10 \%$ (10 casos), quechuas con el $8 \%$ (8 casos) y $4 \%$ (4 casos) serían atacameños.

Paralelo a esto, $18,4 \%$ (23 casos) de los practicantes encuestados indica tener en sus salas de clases a estudiantes afrodescendientes. De dicho valor $47,8 \%$ (11 casos) son extranjeros y $52,1 \%$ (12 casos) chilenos.

Calculando el porcentaje y la frecuencia de los practicantes que afirman tener estudiantes de grupos étnicos en sus aulas, según tipo de dependencia administrativa y financiamiento, podemos 
ver que el 58,4\% (45 casos) se desempeña en establecimientos municipalizados, el 35\% (27 casos) desarrollan sus prácticas en establecimientos particulares subvencionados, mientras que $1,2 \%$ ( 2 casos) en establecimientos privados y $3,8 \%$ ( 3 casos) en instituciones educacionales dependientes de la JUNAEB.

Desarrollando un análisis del porcentaje de casos estudiados que afirman tener alumnos indígenas, respecto de los totales por tipo de dependencia administrativa, podemos ver que el $75 \%$ de los practicantes que se desempeñan en establecimientos municipalizados afirma tener estudiantes de algún grupo étnico. Por otra parte, el 57,4\% de los encuestados que hacen sus prácticas en colegios particulares subvencionados afirman tener alumnos indígenas ${ }^{10}$.

Resulta pertinente evaluar a qué áreas de especialización o carreras de pedagogía pertenecen aquellos practicantes que manifiestan trabajar en aulas con presencia de estudiantes indígenas y extranjeros, para ello elaboramos una tabla (Tabla $\mathrm{N}^{\circ}$ 6) donde se expresan dichos valores.

Los practicantes de Pedagogía en Biología y Ciencias Naturales, con 83,3\% (5 casos), afirma tener alumnos extranjeros y 41,1\% (7 casos) de los practicantes de Pedagogía en Castellano y Comunicación afirma una situación idéntica. Así mismo, los estudiantes de Pedagogía en Educación Básica manifiestan que 59\% (13 casos) son alumnos de otros países, situación que se reitera en el caso de Pedagogía en Educación Básica, quienes coinciden en la afirmación, con 59\% (13 casos).

Por otra parte, en el caso de Pedagogía en Educación Física 19\% (4 casos) manifiesta tener alumnos de origen extranjero, y en los practicantes de Educación Parvularia y Psicopedagogía se aprecia 44,4\% (4 casos), mientras que el 50\% (11 casos) de los practicantes de Pedagogía en Historia y Geografía exponen la situación señalada. Los estudiantes en práctica de Pedagogía en Inglés en $31,8 \%$ ( 7 casos) confirman la presencia de extranjeros y en el caso de los practicantes de Pedagogía en Matemáticas, Computación y Física lo manifiestan en $50 \%$ ( 3 casos).

En consideración a la forma en que se distribuyen los casos que afirman poseer alumnos indígenas, entre las 8 carreras de pedagogía de la Universidad de Tarapacá, $83,3 \%$ ( 5 casos) pertenecen a Pedagogía en Biología y Ciencias Naturales y 76,4 (13 casos) pertenecen a Pedagogía en Castellano y Comunicación. Asimismo, 68,1\% (15 casos) son de la carrera de Pedagogía en Educación Básica, mientras que 23,8 (5 casos) son de Pedagogía en Educación Física y el 77,7\% (7 casos) pertenecen a Educación Parvularia y Psicopedagogía.

Algo similar ocurre con los estudiantes de la carrera de Pedagogía en Historia y Geografía, de estos, $81,8 \%$ (18 casos) manifiesta tener alumnos indígenas en sus aulas, paralelo a esto los estudiantes en práctica de las carreras de Pedagogía en Inglés y Pedagogía en Matemáticas Computación y Física confirman tener alumnos de algún grupo étnico en $54,5 \%$ (12 casos) y $66,6 \%$ (4 casos), respectivamente.

En ese panorama se puede observar que en el caso de estudiantes de Pedagogía en Historia y Geografía efectivamente enfrentan un aula compuesta por estudiantes de diversa procedencia cultural. Ello se manifiesta en que la mitad de los practicantes consultados expresa tener alumnos de otras nacionalidades y por sobre las tres cuartas partes tiene alumnos de pueblos originarios. Observación relevante para ser contrastada con el nivel de formación en competencias interculturales que manifiestan poseer para ejecutar procesos de enseñanza-aprendizaje adecuados a la realidad pluricultural, sobre todo unidades educativas públicas.

Además, estos antecedentes nos permiten manifestar que los estudiantes en práctica de la Universidad de Tarapacá se desempeñan, principalmente, en establecimientos municipales y junto con ello es posible establecer que estos mismos establecimientos agrupan mayoritariamente a los alumnos de extranjeros y miembros de algún grupo étnico. Ello permite plantear una hipótesis preliminar, que afirma que los casos estudiados efectivamente se desenvuelven en contextos caracterizados por ser diversos culturalmente, es decir, multiculturales.

\section{¿Preparados para el desempeño docente en espacios y escuelas fronterizas?}

\section{A. Evaluación de las competencias interculturales por parte de los practicantes encuestados}

Luego de haber descrito y analizado la forma en que los practicantes caracterizan los espacios educativos en los que se desempeñan, creemos importante exponer algunos datos que nos señalen 
Tabla 5. Distribución de practicantes que afirman tener en sus aulas alumnos pertenecientes a otras nacionalidades y grupos étnicos.

\begin{tabular}{|c|c|c|c|c|c|c|c|c|c|c|c|c|c|c|c|c|c|}
\hline \multirow[t]{2}{*}{$\begin{array}{c}\text { Reconocen } \\
\text { alumnos de otras } \\
\text { nacionalidades }\end{array}$} & \multicolumn{2}{|c|}{ Sí } & \multicolumn{2}{|c|}{ No } & \multicolumn{2}{|c|}{$\begin{array}{c}\text { No } \\
\text { contesta }\end{array}$} & \multicolumn{2}{|c|}{ Total } & \multirow{2}{*}{$\begin{array}{l}\text { Reconocen } \\
\text { alumnos de algún } \\
\text { grupo étnico }\end{array}$} & \multicolumn{2}{|c|}{ Sí } & \multicolumn{2}{|c|}{ No } & \multicolumn{2}{|c|}{$\begin{array}{l}\text { No } \\
\text { contesta }\end{array}$} & \multicolumn{2}{|c|}{ Total } \\
\hline & $\mathrm{N}^{\mathrm{o}}$ & $\%$ & $\mathrm{~N}^{\mathrm{o}}$ & $\%$ & $\mathrm{~N}^{\mathrm{o}}$ & $\%$ & $\mathrm{~N}^{\mathrm{o}}$ & $\%$ & & $\mathrm{~N}^{\mathrm{o}}$ & $\%$ & $\mathrm{~N}^{\mathrm{o}}$ & $\%$ & $\mathrm{~N}^{\mathrm{o}}$ & $\%$ & $\mathrm{~N}^{\mathrm{o}}$ & $\%$ \\
\hline $\begin{array}{l}\text { Pedagogía en Biología } \\
\text { y Ciencias Naturales }\end{array}$ & 5 & 83,3 & 1 & 17 & 0 & 0 & 6 & 100 & $\begin{array}{l}\text { Pedagogía en } \\
\text { Biología y Ciencias } \\
\text { Naturales }\end{array}$ & 5 & 83,3 & 1 & 16,6 & 0 & 0 & 6 & 100 \\
\hline $\begin{array}{l}\text { Pedagogía en } \\
\text { Castellano y } \\
\text { Comunicación }\end{array}$ & 7 & 41,1 & 10 & 58,8 & 0 & 0 & 17 & 100 & $\begin{array}{l}\text { Pedagogía en } \\
\text { Castellano y } \\
\text { Comunicación }\end{array}$ & 13 & 76,4 & 4 & 23,5 & 0 & 0 & 17 & 100 \\
\hline $\begin{array}{l}\text { Pedagogía en } \\
\text { Educación Básica }\end{array}$ & 13 & 59 & 9 & 40,9 & 0 & 0 & 22 & 100 & $\begin{array}{l}\text { Pedagogía en } \\
\text { Educación Básica }\end{array}$ & 15 & 68,1 & 7 & 31,8 & 0 & 0 & 22 & 100 \\
\hline $\begin{array}{l}\text { Pedagogía en } \\
\text { Educación Física }\end{array}$ & 4 & 19 & 12 & 57,1 & 5 & 23,8 & 21 & 100 & $\begin{array}{l}\text { Pedagogía en } \\
\text { Educación Física }\end{array}$ & 5 & 23,8 & 11 & 52,3 & 5 & 0 & 21 & 100 \\
\hline $\begin{array}{l}\text { Educación Parvularia y } \\
\text { Psicopedagogía }\end{array}$ & 4 & 44,4 & 5 & 55,5 & 0 & 0 & 9 & 100 & $\begin{array}{l}\text { Educación Parvularia } \\
\text { y Psicopedagogía }\end{array}$ & 7 & 77,7 & 1 & 11,1 & 1 & 0 & 9 & 100 \\
\hline $\begin{array}{l}\text { Pedagogía en Historia } \\
\text { y Geografía }\end{array}$ & 11 & 50 & 11 & 50 & 0 & 0 & 22 & 100 & $\begin{array}{l}\text { Pedagogía en } \\
\text { Historia y Geografía }\end{array}$ & 18 & 81,8 & 3 & 13,6 & 1 & 0 & 22 & 100 \\
\hline Pedagogía en Inglés & 7 & 31,8 & 15 & 68,1 & 0 & 0 & 22 & 100 & Pedagogía en Inglés & 12 & 54,5 & 8 & 36,3 & 2 & 0 & 22 & 100 \\
\hline $\begin{array}{l}\text { Pedagogía en } \\
\text { Matemáticas, } \\
\text { computación y física. }\end{array}$ & 3 & 50 & 3 & 50 & 0 & 0 & 6 & 100 & $\begin{array}{l}\text { Pedagogía en } \\
\text { Matemáticas, } \\
\text { computación y física. }\end{array}$ & 4 & 66,6 & 0 & 0 & 2 & 0 & 6 & 100 \\
\hline
\end{tabular}

la forma en que los practicantes se representan a sí mismos, desde la perspectiva de las competencias pedagógicas necesarias para desempeñarse en contextos multiculturales.

Desde una perspectiva del sujeto evidenciamos la evaluación que hacen los encuestados respecto de su formación inicial docente, mediante la medición de sus juicios acerca de la existencia de asignaturas, que en sus programas de estudio hayan generado aptitudes para desenvolverse en escenarios pedagógicos interculturales.

De esta manera, establecemos una evaluación de los practicantes sobre sí mismos y de las carreras en las que ellos desarrollaron su formación inicial docente.

Inicialmente podemos mencionar que 4,8\% (6 casos) del total de practicantes encuestados reveló sentirse "Altamente Capacitado" para desarrollar actividades pedagógicas en aulas multiculturales; asimismo, 29,6\% (37 casos) definió estar "Capacitado" para ello, mientras que 48\% (60 casos) precisó estar "Medianamente Capacitado".

Solo $12,8 \%$ (16 casos) de los encuestados plantearon no encontrarse capacitados, y solo
$4,8 \%$, es decir seis casos, no contestaron esta pregunta.

Ahora, segmentando la respuesta según sexo, es posible afirmar que de quienes manifiestan estar altamente capacitados $83,3 \%$ (5 casos) son mujeres y $16,6 \%$ (1 caso) son hombres. Respecto de quienes se sienten capacitados $72,9 \%$ (27 casos) son mujeres y $27 \%$ (10 casos) son hombres. Respecto de quienes manifiestan estar medianamente capacitados 68,3\% (41 casos) son mujeres y 31,6\% (19 casos) son hombres.

Del conjunto de practicantes que manifiesta no estar capacitado $62,5 \%$ (10 casos) son mujeres y $31,25 \%$ (5 casos) son hombres. Es importante señalar que quienes no contestan esta pregunta, $50 \%$ (3 casos) son hombres y 50\% (3 casos) son mujeres.

Estos datos nos permiten concluir que las mujeres se sienten más capacitadas que los hombres para desempeñarse en contextos educacionales de carácter multicultural. En la medida en que los practicantes se evaluaban mejor a sí mismos, existía una distancia porcentual mayor entre las mujeres y los hombres; y al acercarnos a la opción 
"Medianamente Capacitado" se apreció que esta tendencia comenzó a decaer, existiendo de todas formas más de 30 puntos porcentuales de diferencia entre hombres y mujeres ${ }^{11}$.

Un aspecto importante es que el número de estudiantes que asume tener algún tipo de capacidad para enfrentar esta clase de contextos es bastante significativo en relación con los 125 casos estudiados. Si integramos los resultados de las diferentes alternativas del sistema de indicadores propuesto a los encuestados, es posible afirmar que el $34,4 \%$ (33 casos) se siente en condiciones óptimas para enfrentar contextos con diversidad cultural y si a ello se suma a quienes definen sentirse medianamente capacitados, se asume que 64,8\% (81 casos) de los casos encuestados asumen estar en condiciones de ejercer en escenarios culturalmente diversos.

\section{B. Autopercepción de los estudiantes en práctica respecto de su nivel de preparación para la actividad educativa en establecimientos con diversidad cultural}

Ahora, intentando obtener datos más específicos de esta autoevaluación desarrollada por los estudiantes en práctica, se indagó en algunos atributos específicos que desde la perspectiva de los mismos practicantes pudieran estar relacionados con las competencias que ellos manifiestan poseer para enfrentar contextos multiculturales.

Algunos de los atributos acerca de los que se les consultó a los practicantes son: el ser Dialogantes; Reflexivos; Críticos; Comprensivos; Tolerantes y Empáticos. Los resultados reportados por la encuesta son claros, ya que 67,2\% (84 casos) de los 125 encuestados definieron ser Tolerantes y el mismo porcentaje definió ser Empáticos. En relación con la misma cantidad de casos estudiados, $62,4 \%$ (78 casos) definen ser comprensivos y de la misma forma, $48,8 \%$ (61 casos) exponen ser Dialogantes. De los encuestados 48\% (60 casos) afirma ser Reflexivo y 37,6\% (47 casos) manifiestan ser Críticos.

Habiendo presentado los antecedentes pertinentes a los atributos que los estudiantes asocian a su perfil, queremos presentar los resultados de los encuestados distribuidos en relación con las 8 carreras en las que ellos se encuentran distribuidos.

De los practicantes de la carrera de Pedagogía en Biología y Ciencias Naturales, que representa el 4,8\% (6 casos) del total de los casos, ninguno se siente altamente capacitado para desarrollarse en aulas diversas social y culturalmente. De igual forma, y en relación con la misma carrera, sostenemos que $16,7 \%$ ( 1 caso) se sienten capacitados, 66,7\% (4 casos) se sienten medianamente capacitados y a la vez $16,7 \%$ ( 1 caso) se siente no capacitado.

En el caso de Pedagogía en Castellano y Comunicación, que representa el 13,6\% (17 casos), es posible sostener que $11,8 \%$ ( 2 casos) están altamente capacitados, 23,5 (4 casos) capacitados, $47,1 \%$ ( 8 casos) medianamente capacitados y $17,6 \%$ (3 casos) afirman no sentirse capacitados para desempeñarse como profesores en contextos multiculturales.

Asimismo, 9,1\% (2 casos) de los estudiantes en práctica de Pedagogía en Educación Básica, que representa el 17,6\% (22 casos), el 9,1\% (2 casos) sostienen estar altamente capacitados, mientras que $31,8 \%$ ( 7 casos) afirma estar capacitado, de los mismos casos, 57,1\% (12 casos) atestigua estar medianamente capacitado y solo un caso, correspondiente a $4,55 \%$, afirma no estar capacitado para enfrentar aulas diversas.

Ahora, al examinar las respuestas de quienes estudian Pedagogía en Educación Física, que representan $16,8 \%$ (21 casos) del total de practicantes, es posible afirmar que $9,5 \%$ ( 2 casos) se concibe altamente capacitado, 28,6\% (6 casos) capacitado, $19 \%$ ( 4 casos) afirma estar medianamente capacitado y 14,3\% (3 casos) afirman no estar capacitados. De este conjunto de practicantes es importante señalar que $28,5 \%$ (6 casos) no contestan.

En el caso de la carrera de Educación Parvularia, que representa el 7,2\% (9 casos) del conjunto de encuestados, podemos afirmar que ninguno de sus practicantes afirma estar altamente capacitado, $44,4 \%$ ( 4 casos) afirma encontrarse capacitado y el mismo 44,4\% señala estar medianamente capacitado. Solo 1 caso, equivalente al $11,1 \%$ señala no encontrarse preparado para ejercer como profesor en aulas multiculturales.

Observando el comportamiento de los estudiantes en práctica de la carrera de Pedagogía en Historia y Geografía, que representan el 17,6\% (22 casos) de los encuestados, podemos señalar que ninguno se siente altamente capacitado para desempeñarse como profesor en aulas diversas culturalmente, pero sí $22,7 \%$ (5 casos) de ellos 
sostiene sentirse capacitado para dicha función; $68,2 \%$ (15 casos) afirma sentirse medianamente capacitado para este ejercicio; solo 2 casos, equivalentes a $9 \%$, manifiestan no estar capacitados para el desempeño pedagógico en aulas multiculturales.

La información anterior descubre que los estudiantes de pedagogía en Historia y Geografía manifiesta la necesidad de una mayor formación en educación intercultural. El hecho de que la mayoría se sientan medianamente capacitado, habla de cierta inseguridad para enfrentar un aula con estudiantes de diversa procedencia cultural. Por consiguiente, a causa de la situación concreta que señalan los datos cuantitativos de que estos estudiantes efectivamente tratan con estudiantes de otras nacionalidades y de pueblos originarios, debe alertar a las instancias correspondientes en vías de mejorar el proceso de formación intercultural.

Al examinar el comportamiento de los practicantes de la carrera de Pedagogía en Inglés, que representa 17,6\% (22 casos) de los estudiantes en práctica encuestados, es posible observar que ninguno de estos indica sentirse altamente capacitado para desempeñarse en la docencia en aulas con diversidad cultural, mientras que $36,4 \%$ (8 casos) de ellos exhiben estar capacitados; al interior del mismo grupo de estudiantes en práctica podemos observar que $54,5 \%$ (12 casos) manifiesta estar medianamente capacitado y 2 casos, equivalentes al 9,09\%, manifiestan no sentirse capacitados.

Continuando con el análisis por carrera, podemos afirmar que en la situación de Pedagogía en Matemáticas, Computación y Física, que representa el 4,8\% (6 casos) del total de los casos estudiados, sostenemos que $33,3 \%$ ( 2 casos) de los estudiantes de la carrera plantean estar capacitado y 16,7\% (3 casos) indica estar medianamente capacitado, de igual forma ninguno de ellos indica estar altamente capacitado, mientras que 50\% (casos) de ellos manifiesta no estar capacitado.

Si observamos los resultados distribuidos por carrera, podemos darnos cuenta de que las carreras vinculadas a las humanidades tienen un mayor porcentaje de estudiantes que se sienten "Altamente Capacitados" o "Capacitados" para enfrentar aulas con diversidad cultural y en las carreras vinculadas a ciencias exactas como las Matemáticas, la Física y la Biología, un número reducido de estudiantes en práctica tienden a evaluar positivamente sus competencias.

\section{Evaluación de la preparación teórica y metodológica de los estudiantes en práctica para el desempeño en espacios educativos con diversidad cultural}

Ahora, intentando indagar en más aspectos asociados a las competencias reconocidas por los practicantes, quisimos averiguar si ellos manifiestan o no tener un conocimiento de aspectos teóricos y metodológicos respecto de temas asociados a contextos diversos culturalmente y por otro lado si consideran tener herramientas para implementar estos conocimientos en sus contextos educativos.

En este esfuerzo pudimos indagar que del total de 125 encuestados $4,8 \%$ ( 6 casos) manifiesta tener un alto conocimiento de herramientas teóricas, metodológicas y técnicas para desempeñarse en contextos con diversidad cultural, mientras que $46,6 \%$ (58 casos) de ellos manifiestan poseer un mediano conocimiento, 37,6 indica tener un nulo conocimiento, mientras que $11,2 \%$ (14 casos) no contesta esta pregunta.

Asimismo, existe 35,2\% (44 casos) de los 125 encuestados que manifiestan incorporar contenidos interculturales en su práctica pedagógica, mientras que $55,2 \%$ (69 casos) manifiesta no hacerlo. El $0,8 \%$ ( 1 caso) de los encuestados no contestó esta pregunta.

Habiendo presentado estos antecedentes queremos señalar que existe $19,2 \%$ ( 24 casos) de 125 practicantes que manifiesta manejar contenidos teóricos, metodológicos y técnicos que reconocen no implementar en los conocimientos asociados a la interculturalidad en su sala de clases. Esto expone la necesidad de incorporar y fortalecer más las capacidades interculturales de los estudiantes en práctica. Ello debe incluir los aspectos teóricos y metodológicos en su formación inicial docente que les permita desarrollar procesos de enseñanza-aprendizaje adecuados a los contextos de diversidad cultural, en donde más de la mitad de ellos se desenvuelven.

Habiendo planteado algunos aspectos relevantes acerca de la autoevaluación que desarrollan los practicantes de sus propias competencias, quisimos indagar en la evaluación qué hacen ellos de su proceso de formación inicial docente, para saber si consideran que este proceso de entrenamiento profesional contribuye o no en la formación de sus competencias en materia intercultural. 
En esta dirección, pudimos ver que 57,6\% (72 casos) de los practicantes afirma que en la carrera que estudiaron tuvieron asignaturas que los prepararon para enfrentar escenarios pedagógicos culturalmente diversos y $34 \%$ (43 casos) de ellos afirma que sus carreras no los prepararon para estos efectos. El 8\% (10 casos) no contestó esta pregunta.

Analizando con más detalle el balance de los estudiantes e intentando ver cómo se comportaron estos datos en relación con cada una de las carreras, podemos ver que en la carrera de Pedagogía en Educación Básica 90,9\% (20 casos) de los practicantes definen haber tenido asignaturas que los prepararon para enfrentar contextos educativos respecto de diversidad cultural. Así ocurre que 77,8\% (7 casos) de los estudiantes de educación Parvularia afirman que en su carrera existen asignaturas orientadas para prepararlos en estas temáticas. De la misma forma, $77,3 \%$ (17 casos) de los estudiantes de Pedagogía en Historia y Geografía manifiestan lo mismo: mientras que 40,9\% (9 casos) de los estudiantes en práctica de la carrera de Pedagogía en Inglés y 33,3\% ( 2 casos) de los estudiantes de Pedagogía en Biología y Ciencias Naturales, afirman tener y $23,8 \%$ ( 5 casos) de los practicantes de Pedagogía en Educación Física afirman no haber tenido este tipo de asignaturas.

Llama mucho la atención que el $100 \%$ de quienes estudian Pedagogía en Matemáticas, Computación y Física señalan no haber tenido alguna asignatura que los preparara para dichos contextos, lo que se hace coherente con las conclusiones desarrolladas anteriormente por el hecho de que los practicantes de las carreras de pedagogía asociadas a las humanidades, los estudiantes tienden a evaluarse de mejor manera que en las carreras vinculadas al área de las ciencias exactas.

También es importante resaltar que sobre el $70 \%$ de los estudiantes de Historia y Geografía haya manifestado tener asignaturas de formación intercultural frente al hecho de manifestar cierta inseguridad en tener competencias interculturales para enfrentar el proceso de enseñanza-aprendizaje mencionado antes. Tal contraste plantea la necesidad de más investigaciones y de un conocimiento más fino, que permita determinar el porqué esa formación intercultural que reciben los estudiantes no logra darles seguridad en competencias adecuadas para enfrentar los contextos educativos pluriculturales en la región (Tablas 6 y 7).

\section{Las competencias interculturales en los practicantes de las carreras de Pedagogía de las facultades de Educación y Humanidades y Ciencias de la Universidad de Tarapacá}

Esta categoría de profesorado es el primero que tiene que asumir e integrar las creencias filosóficas, educativas y sociales que comporta un planteamiento intercultural. Pero este profesorado es también fruto de una educación monocultural, lo que dificulta su capacitación para impartir una educación pluralista $\mathrm{y}$ formar a los y las futuras docentes en este sentido (González et al., 2013).

En las páginas anteriores hemos venido desarrollando una exposición sistemática y descriptiva del comportamiento de los estudiantes en práctica en relación con los diversos aspectos de su formación como profesores y de su desempeño como practicantes de pedagogía. De la misma

Tabla 6. Autoevaluación de las competencias interculturales por parte de los mismos estudiantes en práctica distribuidos por carrera.

\begin{tabular}{|c|c|c|c|c|c|c|c|c|c|c|c|c|}
\hline \multirow[t]{2}{*}{ Carrera profesional } & \multicolumn{2}{|c|}{$\begin{array}{l}\text { Altamente } \\
\text { capacitado }\end{array}$} & \multicolumn{2}{|c|}{ Capacitado } & \multicolumn{2}{|c|}{$\begin{array}{l}\text { Medianamente } \\
\text { capacitado }\end{array}$} & \multicolumn{2}{|c|}{$\begin{array}{c}\text { No } \\
\text { capacitado }\end{array}$} & \multicolumn{2}{|c|}{ No contesta } & \multicolumn{2}{|c|}{ Total } \\
\hline & $\mathrm{N}^{\mathrm{o}}$ & $\%$ & $\mathrm{~N}^{\mathrm{o}}$ & $\%$ & $\mathrm{~N}^{\mathrm{o}}$ & $\%$ & $\mathrm{~N}^{\mathrm{o}}$ & $\%$ & $\mathrm{~N}^{\mathrm{o}}$ & $\%$ & $\mathrm{~N}^{\mathrm{o}}$ & $\%$ \\
\hline Pedagogía Biología y Ciencias Naturales & 0 & 0 & 1 & 16,7 & 4 & 66,7 & 1 & 16,7 & 0 & 0 & 6 & 100 \\
\hline Pedagogía en Castellano y Comunicación & 2 & 11,8 & 4 & 23,5 & 8 & 47,1 & 3 & 17,6 & 0 & 0 & 17 & 100 \\
\hline Pedagogía en Educación Básica & 2 & 9,1 & 7 & 31,8 & 12 & 57,1 & 1 & 4,5 & 0 & 0 & 22 & 100 \\
\hline Pedagogía en Educación Física & 2 & 9,5 & 6 & 28,6 & 4 & 19,0 & 3 & 14,3 & 6 & 28,6 & 21 & 100 \\
\hline Educación Parvularia & 0 & 0 & 4 & 44,4 & 4 & 44,4 & 1 & 11,1 & 0 & 0 & 9 & 100 \\
\hline Pedagogía en Historia y Geografía & 0 & 0 & 5 & 22,7 & 15 & 68,2 & 2 & 9,1 & 0 & 0 & 22 & 100 \\
\hline Pedagogía en Inglés & 0 & 0 & 8 & 36,4 & 12 & 54,5 & 2 & 9,1 & 0 & 0 & 22 & 100 \\
\hline Pedagogía Matemáticas, Computación y Física & 0 & 0 & 2 & 33,3 & 1 & 16,7 & 3 & 50 & 0 & 0 & 6 & 100 \\
\hline Total & & & & & & & & & & & 125 & 100 \\
\hline
\end{tabular}


Tabla 7. Conocimiento sobre teorías, métodos y técnicas de enseñanza intercultural en aulas diversas distribuidas por carrera.

\begin{tabular}{|c|c|c|c|c|c|c|c|c|c|c|}
\hline \multirow[t]{2}{*}{ Carrera profesional } & \multicolumn{2}{|c|}{$\begin{array}{c}\text { Alto } \\
\text { conocimiento }\end{array}$} & \multicolumn{2}{|c|}{$\begin{array}{c}\text { Mediano } \\
\text { conocimiento }\end{array}$} & \multicolumn{2}{|c|}{$\begin{array}{c}\text { Nulo } \\
\text { conocimiento }\end{array}$} & \multicolumn{2}{|c|}{ No contesta } & \multicolumn{2}{|c|}{ Total } \\
\hline & $\mathrm{N}^{\mathrm{o}}$ & $\%$ & $\mathrm{~N}^{\mathrm{o}}$ & $\%$ & $\mathrm{~N}^{\circ}$ & $\%$ & $\mathrm{~N}^{\mathrm{o}}$ & $\%$ & $\mathrm{~N}^{\mathrm{o}}$ & $\%$ \\
\hline Pedagogía Biología y Ciencias Naturales & 0 & 0 & 1 & 16,7 & 5 & 83,3 & 0 & 0 & 6 & 100 \\
\hline Pedagogía en Castellano y Comunicación & 2 & 11,8 & 9 & 52,9 & 5 & 29,4 & 1 & 5,9 & 17 & 100 \\
\hline Pedagogía en Educación Básica & 2 & 9,1 & 17 & 77,3 & 3 & 13,6 & 0 & 0 & 22 & 100 \\
\hline Pedagogía en Educación Física & 0 & 0,0 & 8 & 38,1 & 3 & 14,3 & 10 & 47,6 & 21 & 100 \\
\hline Educación Parvularia & 0 & 0,0 & 7 & 77,8 & 1 & 11,1 & 1 & 11,1 & 9 & 100 \\
\hline Pedagogía en Historia y Geografía & 1 & 5,9 & 7 & 31,8 & 12 & 54,5 & 2 & 9,1 & 22 & 100 \\
\hline Pedagogía en Inglés & 1 & 1,0 & 7 & 31,8 & 14 & 63,6 & 0 & 0 & 22 & 100 \\
\hline Pedagogía Matemáticas, Computación y Física & 0 & 0,0 & 2 & 33,3 & 4 & 66,7 & 0 & 0 & 6 & 100 \\
\hline Total & & & & & & & & & 125 & 100 \\
\hline
\end{tabular}

manera hemos descrito y analizado desde una perspectiva administrativa, social y cultural los contextos educativos donde los casos estudiados se desempeñan.

Habiendo presentado todos estos elementos, planteamos que se hace necesario trazar si los practicantes de pedagogía estudiados cuentan o no con competencias de orden intercultural. Por consiguiente, nos detendremos en algunos antecedentes teóricos y conceptuales acerca de lo que nosotros entendemos por competencias interculturales y de forma paralela comentaremos una selección de los datos presentados y así evidenciar si los casos estudiados cuentan o no con las competencias señaladas.

De esta forma consideramos que un profesor competente es aquel que está capacitado para desempeñarse en situaciones reales en donde los conocimientos y habilidades adquiridos durante su proceso de formación se pueden activar y hacer eficaces (Spencer y Spencer, 2003 y Aguaded et al., 2013). Algo similar plantea Bolívar (2007), quien define que una competencia en educación es una capacidad para ejecutar eficientemente la mayor cantidad de recursos disponibles, sean adquiridos en la experiencia vital o en la formación de pregrado, en el ejercicio de la labor docente en un contexto concreto, esencialmente un espacio multicultural como la región de Arica y Parinacota.

Es así que se sostiene que las competencias que pudieron ser adquiridas teóricamente en espacios de formación solo se activan en la medida en que los docentes se encuentran en espacios que les demandan y exigen dichas aptitudes, actitudes y habilidades.
Por otra parte, la competencia intercultural puede ser concebida como una capacidad adaptativa para incluirse e integrarse a un entorno multicultural o como la capacidad de cambiar y combinar conocimientos, actitudes y comportamientos, con el fin de ser abiertos y llanos a la aceptación e integración de otras culturas (Gómez et al., 2011).

Por tanto, el perfeccionamiento de ella debe llevar al profesor a desarrollar interacciones culturales efectivas que permitan el reconocimiento y respeto por las diferencias socioculturales al interior de su alumnado.

Es importante mencionar que el conocimiento práctico que los estudiantes de pedagogía y los profesores en ejercicio en un espacio culturalmente diverso es único, lo que sumado a su experiencia personal, se transforma en un fundamento en el que se puede sustentar un auténtico sentido de cambio educativo con miras a una educación más inclusiva y tolerante a las diferencias (González, et al., 2013). Lo anterior, implica que el profesorado desarrolle competencias junto con una sensibilidad hacia la educación intercultural necesaria en el ámbito educativo local.

En esta dirección los practicantes de la UTA es evidente que se desempeñan en contextos diversos desde un punto de vista administrativo, social y cultural, por tanto sus respectivos espacios de desempeño les demandan activar conocimientos y habilidades de orden intercultural.

Para fortalecer lo planteado, queremos manifestar que el $48 \%$ (61 casos) de los practicantes de la UTA se desempeñan en establecimientos municipalizados y 37,6 (47 casos) en establecimientos particulares subvencionados. Es decir, el 86,4\% (108 
casos) de los estudiantes desarrolla su práctica en establecimientos que reciben total o parcialmente financiamiento público para su funcionamiento, y esto le otorga un carácter socialmente heterogéneo a sus contextos de desempeño. Además de esto, y quizás lo más contundente, es que el 43,2\% (54 casos) de ellos reconoce tener en sus aulas estudiantes de otras nacionalidades, 63,2\% (79 casos) además reconocen tener en sus aulas estudiantes indígenas y 18,4\% (23 casos) afirma tener en sus espacios educativos estudiantes afrodescendientes.

Por consiguiente, los datos exponen, sin lugar a dudas, una realidad incuestionable: los practicantes de la UTA se desempeñan en contextos altamente exigentes desde el punto de vista de las competencias interculturales. Las aulas que enfrentan no solo tienen estudiantes extranjeros, sino que de diversos grupos étnicos. Recordemos que del total de estudiantes en práctica que afirman tener entre sus alumnos a indígenas, $78 \%$ (78 casos) son aymaras, el 10\% (10 casos) son mapuches, $8 \%$ (8 casos) quechua y $4 \%$ (4 casos) atacameño.

Estos antecedentes referidos a los contextos socioeducativos donde las competencias se activan no solo nos refiere a los mismos contextos, también nos releva que los estudiantes en práctica reconocen la existencia del otro en sus espacios educativos, lo que constituye un factor fundamental a la hora de definir competencias mínimas en educación (González et al., 2013). Además, se puede agregar que los practicantes encuestados no solo reconocen la existencia del otro, sino que son capaces de afirmar en un gran porcentaje que la cultura del otro viene a enriquecer el espacio educativo donde se desempeñan.

Por ejemplo, 69,6\% (87 casos) de los estudiantes encuestados están a favor de incorporar aspectos sociales y lingüísticos de los estudiantes extranjeros, de grupos étnicos y afrodescendientes en sus establecimientos para promover la comunicación al interior de estos, lo que se traduce en una fenómeno de integración y aceptación de la diversidad. Ocurre algo similar al momento de consultarles acerca de la necesidad de dar continuidad a la lengua de los estudiantes extranjeros o de grupos étnicos, porque esto enriquece la vida social y cultural de su establecimiento, en este caso 81,6\% (95 casos) se manifiesta favorable con esta idea.

Esto sin lugar a dudas otorga un potencial a las competencias interculturales de los practicantes, ya que no solo reconocen la existencia del otro, como ya se ha indicado, sino a que a la vez identifican que es importante que las características sociales, culturales y lingüísticas del otro se incorporen al contexto educativo en virtud de la formación de una solución original. Es relevante mencionar que una actitud negativa y deficiente, desde el punto de vista de las competencias, se halla el hecho de negar e invisibilizar al otro; mientras que reconocer su existencia significa una actitud más comprensiva y considerar la cultura del otro en virtud de formar un escenario intercultural es aún más significativo (González et al., 2013 y García, 2008)

Ahora, intentando acogernos a una conceptualización mucho más específica de competencia intercultural, afirmarnos que ella es un conjunto de conocimientos, actitudes, aptitudes, habilidades y valores interculturales, junto con unos comportamientos sociales, afectivos y psicológicos adecuados para relacionarse de manera oportuna, en cualquier momento, situación y contexto, con cualquier persona, sea de la cultura que sea (Aguaded et al., 2013).

Aunque los estudiantes encuestados manifiestan la existencia del otro en sus establecimientos y a la vez son capaces de evidenciar la importancia de formar nuevos espacios educativos considerando sus rasgos culturales, sociales y lingüísticos, creemos que es pertinente indagar en otros aspectos asociados a lo que los mismos practicantes manifiestan respecto de sus capacidades para actuar planificada y sistemáticamente en estos contextos. Lo anterior es algo no menor si se considera que un profesor debe estar capacitado para promover innovaciones curriculares e incorporar contenidos de temas culturales orientados a la diversidad, pero también deben desarrollar nuevas estrategias de enseñanzaaprendizaje que induzcan al alumnado a la reflexión y al análisis intercultural (González et al., 2013).

Por un lado, contamos con que $82,4 \%$ (103 casos) manifiestan tener capacidades para desempeñarse en contextos de diversidad cultural. No obstante, en nuestro estudio quisimos ir más allá y averiguar la actitud de los practicantes frente a algunas afirmaciones que señalan la posesión de competencias que superan los factores valóricos e ideológicos, alcanzando connotaciones asociadas a la disposición, la planificación y la sistematicidad en el trabajo pedagógico en contextos multiculturales.

De esta forma se pudo constatar que 52,8\% (66 casos) de los practicantes manifestó generar alternativas de enseñanza para los estudiantes de otras culturas, incluso cuando el establecimiento educacional no se los indica. Por otro, al consultarles 
si ellos consideran estar capacitados para eliminar el prejuicio en su práctica profesional, se observa que $77,6 \%$ (97 casos) señala trabajar para eliminar el prejuicio en su ejercicio como futuro docente. Asimismo, fue posible observar que más de la mitad de los practicantes $(52,8 \%, 66$ casos) se muestran favorables con la idea de que necesitan reforzar y adquirir nuevas herramientas para trabajar en contextos diversidad cultural.

Lo anterior les otorga un potencial autocrítico, lo que les confiere elementos competitivos desde el punto de vista de las competencias interculturales, porque al considerar los límites de sus capacidades, abren la posibilidad de incorporar los elementos sociales y culturales del otro en su práctica pedagógica. No olvidemos que una competencia pedagógica intercultural se refiere también a la idea de que se debe atender y educar para la diversidad, siendo el docente consciente de sus propias creencias, valores, prejuicios y concepciones, además de comprender el mundo de la manera en que lo comprenden quienes recepcionan su acción pedagógica (Mc Davis et al., 1992).

Sin lugar a dudas, lo que aquí se ha presentado requiere ser reforzado con información de otras instituciones de educación superior. Ello es necesario para saber los contenidos de las disposiciones manifestadas por los practicantes. Es decir, aunque estamos enterados de que los encuestados se muestran favorables a la idea de generar alternativas culturales para estudiantes de otras nacionalidades y culturas, se requiere saber cuáles son los contenidos y los métodos asociados a estas iniciativas individuales. Lo antes dicho será una respuesta sistematizada en la segunda fase de nuestro estudio que entregará información valiosa pertinente a la forma en que están enfrentando los futuros docentes las nuevas demandas culturales en el espacio educativo.

\section{Comentarios finales}

Finalmente, es factible agregar que si bien la educación intercultural apareció en los países andinos, para atender las demandas de pueblos indígenas (Chiodi 1990) entre los 80 y los 90 del siglo pasado, hoy esa modalidad educativa debe ser transversal a toda la población. Es imperativo reconocer el hecho de que enfrentamos una sociedad en permanente proceso de construcción no solo con los aportes tradicionales sino también con el aporte de diferentes culturas que hoy se reconocen gravitantes (Sáez 2006). Es el caso de la región de Arica y Parinacota, cuya situación pluricultural se patentiza no solo con la presencia de grupos criollos, de pueblos originarios, afrodescendientes y migrantes en distintas épocas, sino también por su condición fronteriza en el extremo norte de Chile. Esta última condición, además, no solo patentiza interacciones e incidencias culturales cotidianas, de una dinámica sociocultural particular de relaciones interculturales diversas. También demanda una educación intercultural pertinente y constructiva.

Los datos generados a partir de las respuestas de los profesionales practicantes de la carrera pedagógica de la UTA encuestados en este estudio en relación con la práctica de una educación intercultural, no solo reafirman la situación pluricultural de las aulas en la región que se ha aludido previamente. También plantean una alerta a la atención de esa modalidad educativa en la formación que entrega nuestra Universidad. Aun cuando el estudio manifiesta una efectiva formación en las competencias interculturales y de una autopercepción positiva para desarrollar labores pedagógicas en aulas pluriculturales de los profesionales en práctica de las distintas pedagogías, es importante realizar estudios e investigación acerca de qué tipo de formación intercultural están recibiendo, cómo se está ejecutando esa formación en las distintas carreras, qué nivel de formación reciben los estudiantes de pedagogía, con qué recursos humanos se enfrenta esa demanda, etc. Todo ello con la finalidad de elevar el porcentaje de profesionales competentes en la formación intercultural.

Nuestra Universidad de Tarapacá está en un espacio privilegiadamente pluricultural de activos y permanentes procesos interculturales. Por tanto, es un desafío permanente pensar en la educación intercultural como un proceso de estudio y aprendizaje interepistémicos para todos sus estudiantes, especialmente los de pedagogía. En otras palabras, de lo que se trata es ver el tema de manera integral, acuciante y cercana al contexto sociocultural de nuestra región; no lejano, como nos lo recuerda Walsh (2009) desde la educación intercultural crítica. 


\section{Referencias Citadas}

Aguaded, E.

2006 "Diagnóstico e intervención para el desarrollo de competencias Interculturales". Extraído: Diciembre de 2013 de http://evaaguadedramirez.blogcindario. com/2006/10/00003-diagnostico-e-intervencion-para-eldesarrollo-de-competencias-interculturales.html. 2006.

Aguaded, E.; de la Rubia, P.; González E. y Beas M.

2012 "Análisis de las competencias interculturales en la Formación del profesorado". Revista Electrónica de Investigación y Docencia (REID), número monográfico, octubre, 2012, 156-171. http://www.revistareid.net/monografico/n2/ reidm2art8.pdf

Andreucci, $\mathrm{P}$.

2013 "La Supervisión de Prácticas Docentes: Una Deuda Pendiente de la Formación Inicial de Profesores". Estudios Pedagógicos XXXIX, N 1: 7-26, 2013.

Becerra, G.

2005 "Necesidades de formación docente en la zona de frontera: una exploración inicial". Aldea mundo, año 9 $\mathrm{N}^{\circ}$ 17. Pp. 33-40. 2005.

Bolívar, A.

2008 Ciudadanía y Competencias básicas. Sevilla: Fundación ECOEM.

Chodi, F.

1990 "Avances, problemas y perspectivas de la pedagogía bilingüe intercultural”. En La educación indígena en América Latina. Tomo II. Quito: PEBI / Abya Yala.

Correa, E.

2011 "La práctica docente: una oportunidad de desarrollo profesional". En Revista Perspectiva Educacional, Vol. 50. $\mathrm{N}^{\mathrm{o}} 2$, pp. 77-95.

Díaz, A.

2012 "Un recuento histórico de las poblaciones Aymaras del Norte de Chile. Siglos XIX y XX”. Revista Atenea No 504 (En prensa).

Galvis, R.

2007 De un perfil docente tradicional a un perfil docente basado en competencias. Universidad Pedagógica Experimental Libertador - Instituto Pedagógico de Caracas. Caracas, 2007-11-18).

\section{Notas}

1 En el 2010 los inmigrantes de la región de Arica y Parinacota representaban el 3,22\% de toda la población migrante del país y el 6,10\% de la población de la región. Departamento de Extranjería y Migración, Chile, 2011.

2 La encuesta CASEN, del 2011 arroja que el 26,3\% de la población de la Región de Arica y Parinacota pertenece a un pueblo originario ocupando el segundo lugar luego de La Araucanía con $32,1 \%$. El pueblo aimara es el segundo grupo originario con mayor población del país, llegando a representar el 7,2\% de la población nacional. Informe de Política Social, 2013. Ministerios de Desarrollo Social de Chile.

3 Para conocer acerca del desarrollo de la educación intercultural bilingüe en la región consulte el trabajo de Mondaca y Gajardo publicado en Diálogo Andino $\mathrm{N}^{\circ} 42$,
Geeregat, $\mathrm{O}$.

2012 "Procesos de formación inicial docente en contextos multiculturales: inclusión y exclusión”. Estudios Pedagógicos XXXVIII, Nº 1: 345-351, 2012.

Gimeno, J.

Educar por competencias, ¿qué hay de nuevo?, Ediciones Morata, S.L. Madrid.

González, O.; Berríos, Ll. y Buxarrais, M.

2013 "La sensibilidad del profesorado hacia el modelo de educación intercultural: Necesidades, situación actual y propuesta de un instrumento de medida". Estudios Pedagógicos XXXIX, No 2: 147-164, 2013.

McDavis, R.J.

1992 "Multicultural counselling competencies and standards: A call to the profession". Journal of Counseling \& Development, Vol. 1 (70), 477-486.

Mondaca, C. y Gajardo, Y.

2013 "La educación intercultural bilingüe en la región de Arica y Parinacota, 1980-2010”. Diálogo Andino No 42 , 2013.

Mondaca, C.; Rojas, A., Siares, C., Sánchez E.

2017 "Inclusión, adscripción e identidad étnica en estudiantes de la Universidad de Tarapacá, frontera norte de Chile". Revista Diálogo Andino No 53, pp. 39-150.

Sáez Alonso, Rafael

2006 "La educación intercultural". En Revista de Educación №339, pp. 859-881. Universidad Complutense de Madrid. En línea: http://www.revistaeducacion.mec.es/re339/ re339a37.pdf

Sue, D. \& Sue, D.

1990 Counseling the culturally different: theory and practice. John Wiley \& Sons Inc. Nueva York.

Walsh, Catherine

2009 Interculturalidad crítica y educación intercultural. (Artículo ampliado de la ponencia presentada en el Seminario "Interculturalidad y Educación Intercultural", organizado por el Instituto Internacional de Integración del Convenio Andrés Bello, La Paz, Bolivia). En línea: https:// redinterculturalidad.wordpress.com/2014/02/06/interculturalidad-critica-y-pedagogia-decolonial-catherine-walsh/ comment-page-1/
2013. Denominado "La educación intercultural bilingüe en la región de Arica y Parinacota, 1980-2010".

4 La región de Arica y Parinacota posee el segundo porcentaje de personas pertenecientes a pueblos originarios, por lo que es importante mencionar que este grupo presenta las mayores tasas de pobreza y los menores grados de inclusión. Informe de Política Social, 2013. Ministerio de Desarrollo Social de Chile.

5 En la Primera Consulta Ciudadana acerca de la Discriminación realizada en Chile en el 2013, del 31 $\%$ de actos discriminatorios arbitrarios el $25 \%$ fue por nacionalidad. Además, el porcentaje más alto, 33\% de actos discriminatorios, se encuentra en el norte del país, en comparación al sur que solo posee $17 \%$. Finalmente el tramo de edad que concentra el mayor porcentaje de 
discriminación es aquel que va de los 18 a los 25 años, seguido por el de $<18$ años con $27 \%$.

6 Esta unidad conserva y resguarda los registros académicos de todos los estudiantes de la Universidad de Tarapacá.

7 Si se observa con detención en los datos referidos a la población que afirma pertenecer a algún grupo étnico y quienes se adscriben a alguna etnia en específico existe una diferencia, ya que hay estudiantes que señalaron pertenecer a algún grupo en particular pero en la pregunta "Pertenece usted a algún grupo étnico" no responden.

8 Para mayores antecedentes por la adscripción étnica en la Universidad de Tarapacá, revisar Mondaca et al., 2017

9 No se incluyen los estudiantes practicantes de los establecimientos particulares y dependientes de la JUNJI, porque al tener 4 y 2 practicantes, respectivamente, no son estadísticamente significativos para ser comparados con los valores de los municipalizados y los particulares subvencionados.

10 No incluimos aquí a los estudiantes practicantes de los establecimientos particulares y dependientes de la JUNJI, porque al tener 4 y 2 practicantes, respectivamente, no son estadísticamente significativos para ser comparados con los valores de los establecimientos municipalizados y los particulares subvencionados.

11 Esta tendencia se fortalece aún más cuando preguntamos si los practicantes manejan o no conocimientos teóricos y metodológicos respecto de la enseñanza en contextos multiculturales y pudimos observar que las mujeres asumen manejar, en mayor medida que los hombres, este tipo de conocimientos. El análisis del manejo de teorías y métodos, como la forma que los estudiantes tienen de implementarlos, se desarrolla con más detalle en las siguientes páginas del presente artículo. 